ISSN 1112-9867

http://www.jfas.info

\title{
THE RELEVANCY BETWEEN STRUCTURAL FACTORS AND ENRICHING THE MANAGERS OF SADERAT BANK BRANCHES IN TEHRAN PROVINCE
}

\author{
N. Tabrizi
}

Department of Bank Saderat Iran, Tehran, Iran

Published online: 05 June 2016

\begin{abstract}
The present investigation Is done to determine the structural factors and prioritize the efficacy of each factors on enriching the managers of Saderat bank branches of Tehran province. The present investigation is practical considering its purpose, and descriptive (correlation kind) considering data assemblage. Statistical population is the managers of the entire 602 branches of Saderat bank in Tehran. The sample volumes of 300 branches were calculated. 300 questionnaires were distributed; the 255 questionnaires were evaluated by SPSS software in order to have a stable statistical population. The results indicate that "commission conferring" is considered the most effective factor on enriching from respondent's point of view, among other structural factors.
\end{abstract}

Keywords: enriching; structural factors; managers

Author Correspondence, e-mail: tabrizi.nooshin@yahoo.com doi: http://dx.doi.org/10.4314/jfas.8vi2s.20

\section{INTRODUCTION}

Today, Organizations must be managed in a quite competitive atmosphere with cataclysmic mutations. In such an atmosphere, the managers lack the opportunity to control the employees and they should be spent most of their time and energy to recognize the internal and external 
atmosphere of the organization and leave the rest of the daily routine to the employees. The employees will be able to handle the responsibilities well, when they have the required knowledge, motivation, abilities and skills and be familiar with organizational goals. The instrument which could assist managers in this field is the process of "Enriching". Enriching is one of the integral parts of managing and is the center of analysis and tries to improve the control of managing in a higher quality and democracy. Enriching; causes potential situation insure working instructions and has enclosed link with human resources management, philosophically. Enriching arises when the employees figure the concept of authority out. Most of analysts believe that the entire investments, especially the human resources of the companies must be activated, in these days of competitive essence. Enriching Not only does not cause or descend directional puissance but also plays an essential role in simplifying, renovation and its progress. Since Enriching is at the service of a specific purpose and is a tool to achieve a goal, not being a goal itself, we can help employees to help themselves and their organization, with managing Enrichment, and to give meaning and the feeling of being proud in order to do the task in the best possible way. Therefore, it's due to the organization managers to precede initial and suitable foundation in the environment of organization and to make sure that they provide the best use of human resources and maximum productivity. Having authentic resource management and efficient, motivated and creative human forces is one of the biggest concerns for today organizations. The expansion and progressive growth of IT and knowledge and the close and complicated contest which rules the market, forces the organizations and financial institutes to use managers who are talented and spunky enough in utilizing these resources, in order to have authority in the field and to reach rational profit making and fine customer orientation these days, although having capable stuff is considered a competitive advantage for the organizations, it should be admitted that the necessity of having connoisseur and capable managers who can have optimized management on resources and utilize them in chance making situations, is not ignorable. Banks are among the financial institutes which are exposed at the danger of boisterous peripheral damages. The variety of products and services given by other financial establishments, forces these institutes to pay especial attention to the whole time changing customer's requests in order to keep them. These 
institutes therefore, are in need of creative cerebration and accurate programming in the precinct of market and customer. It is very obvious that one of the most effective options on the permanence of banking system is the continuity of loyal and precious customers using bank services for years. The dominant circumstances on customer's business activity style and their connection substance, forces the banks to use committed mangers and experts to analyze perfect customers and to use practical methods to attract them in order to have special services for them. Therefore, recognizing and analyzing customer's demands, in order to keep them loyal to banking system and keeping them active in their relevancy with bank, is a significant factor. This fact requires eligible and capable managers to be the effect provenance by preparing suitable bases in banking system and creating nicety and capability culture, and by analyzing and revising customer's demands, recognizing their requirements and pathology. The fact of making sure that customers are pleased with bank services and evaluating them is one of the effective steps on attracting customers and requires analyses and accurate programming. The attendance of capable managers who are able to make decisions in different sections of the bank, is absolutely essential managers, who can take steps on the path of flourishing and growth of the organization by recognizing available potentials and focusing on unknown markets and to make bank reach it's profit making norms by recognizing threats, using available opportunities and making decisions and making decisions. Reaching the considerable goals of bank by6 using directional strategies in order to educate managers who facilitate the path of reading these goals, is an undeniable necessity. Therefore, the present investigation is trying to analyze the effective factors on enriching the managers of Saderat-Iran bank branches. The structure is involved more than organizational chart in enriching an organization and staff. The parameters that people will do must be clear. The structure effects on the definition of discretion; it also effects on the way the purposes are determined, how decisions are made, how function and action are performed and how the staff are trained. Structuring for enriching must be gradual. Firstly, staff cannot manage to deal with changes applied one-off. Secondly, no one could predict the whole structural factor that organization needs. The result of analyzing 10 companies is ' 3 ' key points for enriching staff and organizations to work in the situation and to reach jobs and is explained at the 
following: First and most important of all, is that the beginning is to share any kind of perceptual conceptual information. Once the information sharing culture and trust is made, the structure should be used to create dependency and teams should be expanded for replacing the pecking order.

\subsection{Purpose}

- Determining structural factors effective on enriching managers of Saderat-Iran bank branches in Tehran province.

- Prioritizing the efficacy of each factor on enriching the managers of Saderat-Iran bank branches in Tehran province.

\subsection{Theories}

-There is meaningful connection between basic (structural) factors and enriching the managers of Saderat-Iran bank branches in Tehran province.

-There is enough evidence proving with the fact below:

There is a linear connection structural factors and enriching the managers of Saderat-Iran bank branches in Tehran.

\subsection{Teorical structure}

By the branch of organization structure, we need the whole element and factors and physical and factitious circumstances which are related to each other disciplinary formulary and in a special order and form the structure, format, context, body (frame work) or the physique of the organization, therefore the entire corporeal and informational resources are considered inside the branch of organization structure. In other words, they are considered not live factors of the organization once they run toward the generalized structure of the organization in a special built. 
Table 1. Dimensions and structural factors effective on enriching, according to the history of investigation

\begin{tabular}{|c|c|c|}
\hline $\begin{array}{c}\text { Effective factors on } \\
\text { enriching }\end{array}$ & Investigators/year & references \\
\hline Award & Jorn Flohr Nielsen, Christian Preuthun Pedersen (2003) & (9) \\
\hline $\begin{array}{c}\text { Expressiveness of the } \\
\text { job }\end{array}$ & Azize Ergeneli, Guler Saglam Ari, Selin Metin (2007) & (3) \\
\hline Job enrichment & Jorn Flohr Nielsen, Christian Preuthun Pedersen (2003) & (9) \\
\hline Appropriateness & $\begin{array}{l}\text { Azize Ergeneli, Guler Saglam Ari, Selin Metin (2007), } \\
\text { Tae- Yeol Kim, Minsoo Kim. (2012), Catherine } \\
\text { Cheung, Tom Baum, Alan Wong (2012) }\end{array}$ & $\begin{array}{l}(3),(14), \\
(4)\end{array}$ \\
\hline Authority & Esther Gal-Or, Raphael Amit (1998) & (6) \\
\hline $\begin{array}{l}\text { Having access to the } \\
\text { information and } \\
\text { processes }\end{array}$ & $\begin{array}{l}\text { Jorn Flohr Nielsen, Christian Preuthun Pedersen } \\
\text { (2003), W.Alan Randolph (2004), Shazia Nauman, } \\
\text { Azhar Mansur Khan, Nadeem Ehsan (2010) }\end{array}$ & $\begin{array}{l}(9),(15) \text {, } \\
\quad(13)\end{array}$ \\
\hline Delineation of duties & Abby Kahaleh, B. Pharm, Caroline Gaither (2007) & (1) \\
\hline $\begin{array}{l}\text { Organizational } \\
\text { structure }\end{array}$ & W.Alan Randolph (2004) & $(15)$ \\
\hline Education & $\begin{array}{l}\text { W.Alan Randolph (2004), Debbie Massey, Debora } \\
\text { Osborne (2004) }\end{array}$ & $(15),(5)$ \\
\hline Purposes & $\begin{array}{l}\text { W.Alan Randolph (2004), Abby Kahaleh, B. } \\
\text { Pharm, Caroline Gaither (2007) }\end{array}$ & $(15),(1)$ \\
\hline Function & $\begin{array}{l}\text { Jorn Flohr Nielsen, Christian Preuthun Pedersen } \\
\text { (2003), W. Alan Randolph (2004), Shazia Nauman, } \\
\text { Azhar Mansur Khan, Nadeem Ehsan (2010), Lame C. } \\
\text { Jay, Kevin L. Webb, Chiharu Ishida (2009), Tae- Yeol } \\
\text { Kim, Minsoo Kim (2012), Kenneth J. Harris, Anthony } \\
\text { R. Wheeler, K. Michele Kacmar. (2009) } \\
\text { Adam Rapp, Michael Ahearne, John Mathieu, Niels }\end{array}$ & $\begin{array}{l}(9),(15), \\
(13),(11), \\
(14),(10), \\
(2),(16)\end{array}$ \\
\hline
\end{tabular}


Schillewaert (2006), Yuosre F.Badir, Bettina Buchel,

Christopher L.Tucci. (2012)

\begin{tabular}{|c|c|c|}
\hline Leadership style & $\begin{array}{l}\text { Shazia Nauman, Azhar Mansur Khan, Nadeem Ehsan } \\
\text { (2010), Adam Rapp, Michael Ahearne, John Mathieu, } \\
\text { Niels Schillewaert (2006), Esther Gal-Or, Raphael } \\
\text { Amit (1998) }\end{array}$ & $\begin{array}{l}(13),(2), \\
(6)\end{array}$ \\
\hline Connections & $\begin{array}{l}\text { W. Alan Randolph (2004), Yuosre F. Badir, Bettina } \\
\text { Buchel, Christopher L. Tucci. (2012) }\end{array}$ & $(15),(16)$ \\
\hline Co-discernment & W.Alan Randolph (2004) & (15) \\
\hline Control & $\begin{array}{l}\text { Lame C. Jay, Kevin L. Webb, Chiharu Ishida. (2009), } \\
\text { Esther Gal-Or, Raphael Amit (1998) }\end{array}$ & $(11),(6)$ \\
\hline Job satisfactory & $\begin{array}{l}\text { Kenneth J. Harris, Anthony R. Wheeler, K. Michele } \\
\text { Kacmar. (2009) }\end{array}$ & $(10)$ \\
\hline Focusing on customers & $\begin{array}{l}\text { Shazia Nauman, Azhar Mansur Khan, Nadeem Ehsan } \\
\text { (2010), Adam Rapp, Michael Ahearne, John Mathieu, } \\
\text { Niels Schillewaert (2006),John Sundbo(1996) }\end{array}$ & $\begin{array}{l}(13),(2), \\
(8)\end{array}$ \\
\hline Competitive force & $\begin{array}{l}\text { Shazia Nauman, Azhar Mansur Khan, Nadeem Ehsan } \\
\text { (2010), Adam Rapp, Michael Ahearne, John Mathieu, } \\
\text { Niels Schillewaert (2006), }\end{array}$ & $(13),(2)$ \\
\hline $\begin{array}{c}\text { Reengineering } \\
\text { processes and systems }\end{array}$ & Jorn Flohr Nielsen, Christian Preuthun Pedersen (2003) & (9) \\
\hline
\end{tabular}

-Operating definition of variables and key words

Organization: Is a system formed from activities done in groups of 2 or 3 who are intentionally harmonized with each other and this intentional harmonization points out to 4 common and generalized aspect in the entire organizations which are the concord of the effort, common goal, sharing duties and the pecking order of authority and these 4 factors are mentioned as organization structure. Basic (structural) factors (difficulty officialdom and focus) are. The official communication among people, job standing and organizational posts, 
accessibility to structural information, expressiveness of responsibility(the way things are done)expressiveness of the job, how to attribute the resources, legs and rules, the mechanisms of obedience and performing the rules, harmonizing activities with each other (3), instructions and bylaws, access to the information and controlling processes, the supervision domain, focus, the official communication among people, the expertism of organization, complication(vertical, horizontal, spatial), profession of the organization, staff relation Enriching: Is creating a situation to have high working motive by developing a self-effectiveness feeling.

Awarding system: There are some social and inner awards which are different from payment and premium. Social awards include recognition and appreciation from staff, inside and outside organization. Intrinsic awards come from personal feelings such as self confidence contentment and succession at work. Organizational awards are divided to two kinds, inner and outer. Outer awards include pecuniary awards, and social ones cause it's the result of peripheral circumstances. Inner awards include intrinsic awards because they form due to the directional involvement of inner causes.

Job designing: This category deals with actions which include changing and reforming special jobs or systems related to them and the purpose of taking those actions is improving the quality of staff experience in their jobs and productivity at work.

Organization structure: The structure of the organization is consisted of three parts called duty, reporting and adoption in which bureaucratic is done in its format. In fact, the structure of the organization means to set and harmonize staff actions in a way that leads to the fulfilment of organization purposes. The structure of organization is the result of combination of complication, officialdom and focus in different organizational forms such as stable structure. Vocational extension: Means to create more variety in staff job through combining specialized duties which are hardly comparable.

Vocational enriching: According to Hersberg's founded theories, this special theory is in need of job reforming in a way that an employee has a chance to feel success recognition, motivational actions, accountability and promotion. These properties get related to the intended job through vertical uploading. Therewith creating extra activities which are in same 
level of difficulty and are almost similar former activities of staff, in horizontal staff, more responsibilities will be applied to staff. In other words, staff do the routine related to their headmen.

Organizational justice: It's mainly about the individual's level of understanding about the fact that whether they are treated well or not.

Purpose: The thing an individual is looking to gain, is called purpose, target or the reason why something is done.

Decision making: This category is a mean to reach goals. Therefore, it needs determination and choosing suggested a solution which leads to the creation of ideal situation to succeed.

Group: Two or more people who are in interaction with each other and have an assortment of norms and common goals and a common quiddity, are called a group.

Team: Teams are working groups which have reached evolution and its quiddity is indicated through the common commitment among it's members with out commitment, groups act like individuals while with commitment, groups turn in to capable and functional forces who work together.

Trust: Mutual belief and faith toward other's behavior and goals.

Communications: Exchanging information between sender and receiver and how to understand the context, among people who are a part of this process. Analyzing this exchange indicates that communication is a mutual process in which the progression of related factors in it, is greatly seen.

\section{ATTITUDES OF ENRICHING}

Enriching can be considered as an international compilation of "knowledge and insight" and so the structural attitude of enriching can be extended to education for knowledge and the functional attitude of enriching can be expanded for utilizing and the moral attitude of enriching can be considered in 2 other life skills educations, specially group style living. -structural attitude:

The studies of structural attitude are mainly about the fact that what methods and means the managers prepare in order to enrich their staff using them or developing enough bases at work 
atmosphere (Spritzer and Donson 2005:34). Basically, every organization -in order to do it's mission in the best way-first, must form it's inner structure which is done through structuring rules and instructions. Therefore, we are facing conceptual structure "becoming official" which is becoming standard and formalizing human behavior in organization, according to the definition (12). And whether the formalizing is in organization, it mostly emphasizes on rules and communication dealing with instructions.

Functional attitude of enriching:

If skilled services at high range, expertise at knowledge (technical) and more dependency toward other jobs are considered among the conceptual structure of becoming professional, it will be considered that every organization must be on the way of becoming professional to make sure that the missions are done accurately. The path of becoming professional expands from inside of every organization toward outside (outer environment) and accordingly should have special authority

Moral attitude of enriching:

The most complete stage is considered meeting the needs and responding to the problems of environment (people).

-psychological attitude of enriching:

This attitude focuses on comprehension and how the staff comprehends from Enriching This attitude is related conditions, feelings and people's beliefs toward organizational job and process of increasing inner motivation of job is the definition considered for it. It consists of mechanical and organic attitude.

*Mechanical attitude: Enriching means to leave authority to the lower grads staff.

*Organic attitude: Enriching means to venture, progress and change and also believing in staff and having tolerance toward their mistakes and has five aspects: appropriateness, the feeling of being effective, trust, operative dependency and expressiveness feeling.

-motivational attitude of enriching:

This aspect of enriching is known as enabling or creating motivation through self-esteem. Enabling is developing an opportunity to increase people's motivation for doing their responsibilities by increasing self-steam or decreasing feeling inoperative. In this attitude the 
target, is enriching and strategy is to increase self-adequacy.

-Relational attitude of enriching:

This attitude is described as a mechanical and up to down process. In this attitude enriching does not happen unless the upper levels of the hierarchy of the organization, share their authority with other people in the same hierarchy of organization. In this attitude, the role of managers and guides in organization need to be analyzed for enriching staff because they have a considerable effect on staff's psychological comprehension from enriching in this attitude the purpose of enriching is strengthening and the strategy is distributing authority in organization.

\section{EXPERIMENTAL}

Due to the fact that the purpose of this investigation is determining structural causes and factors effective on enriching the managers of Saderat-Iran bank branches in Tehran, therefore, in order to determine this role and communicate, descriptive investigation has been used. This way, the investigator is able to analyze the relevance between different variables and also to describe circumstances, if necessary. In the present investigation the variables of structural factors are independent and the variable "enriching", is dependent. The statistical population is the entire branches of Saderat bank in Tehran. According to the gained statistics, statistical population is around 602 branches which is considered in a limited way. Therefore, in order to calculate the sample volume-required for the investigation the following formulas have been used:

$n=\frac{N \times Z \alpha^{2} / 2 \times P(1-P)}{\varepsilon^{2}(N-1)+Z \alpha^{2} / 2 \times P(1-P)}$

$$
n=\frac{602 * 1.96 * 1.96 * 0.5 * 0.5}{602 * 0.04 * 0.04+1.96 * 1.96 * 0.5 * 0.5}=300
$$

Among strategies structure and mentioned methods, different tools have been used for gaining the required data. These tools are internet and library analyzing which has been the base of 
designing the initial model of investigation. Another tool for gathering data, is designing and performing questionnaire type, designed for this investigation, is closed and has been performed utilizing "Likert's 5 options" method which is considered as one of the most common measurement modules. For gathering adequate data, 300 questioners were disturbed and 260 were received. 250 of received ones were considered appropriate enough to analyze. In order a stable sample of statistical population, the 255 received questionnaires were evaluated by SPSS software. Alpha was calculated for different parts of the questionnaire and the amounts are indicated in Table 2. All gained numbers indicate that different parts of questionnaire have enough stability and are trustable.

Table 2. Indexes of Cronbach's alpha for the whole questions of questionnaire

\begin{tabular}{lccc}
\hline $\begin{array}{l}\text { Category } \\
\text { name(context) }\end{array}$ & number of questions & Reliability & \multicolumn{2}{c}{$\begin{array}{l}\text { Measurement } \\
\text { number }\end{array}$} \\
\hline structural factors & 31 & 0.92 & $70 \%<$ \\
\hline Enriching & 5 & 0.86 & $70 \%<$ \\
\hline
\end{tabular}

\section{DATA}

Descriptive indices such as average and standard deviation for the entire variables of the investigation are discussed here.

Table 3. Descriptive statistic of questionnaire queries, average and standard deviation related to structural factors

\begin{tabular}{rccc}
\hline \multicolumn{4}{c}{ Structural factors } \\
\hline Row & factor & Average & Standard deviation \\
\hline 1 & Award & 2,80 & 0,79 \\
\hline 2 & Expressiveness of the job & 2,93 & 0,84 \\
\hline 3 & Job enriching & 3,05 & 1,05 \\
\hline 4 & Authority conferment & 3,28 & 0,93 \\
\hline 5 & Access to the information and & 2,78 & 0,81 \\
\hline
\end{tabular}




\begin{tabular}{cccc}
\hline \multicolumn{5}{c}{ controlling processes } & \\
\hline 6 & Relationships & 2,95 & 0,79 \\
\hline 7 & Control & 2,92 & 0,90 \\
\hline 8 & Access to the resources & 2,59 & 0,94 \\
\hline 9 & Rules and instructions & 2,75 & 0,91 \\
\hline 10 & Organizational structure & 2,54 & 0,90 \\
\hline 11 & Educating staff & 2,97 & 0,88 \\
\hline 12 & Managing function & 2,57 & 0,84 \\
\hline 13 & Complication & 2,95 & 0,86 \\
\hline 14 & Officialdom & 3,19 & 0,89 \\
\hline 15 & Focus & 2,83 & 0,95 \\
\hline
\end{tabular}

Table number 3 indicates the condition of structural factors work with analyzed people. According to the average indexes and calculated standard deviation, it can be discussed that the averages of authority conferment, job enrichment, officialdom in the present investigation, is more than average limit (which is 3 according to Likret's 5-point range). The variable with higher score has more importance. Therefore, from the collection of structural factors effective on enriching, the factor "authority conferment with the average of 3.28 is recognized as the most effective factor on enriching from responder's point of view.

Analyzing theory Pierson's correlation test:

there is a meaningful relevancy between structural factors and enriching the managers of Saderat bank branches in Tehran. In order to perform theory test, the theory of correlation must be proved and then, provided that there is a meaningful correlation, regression can be used to recognize the amount of effects of structural factors on enriching.

Theory $\mathrm{H}_{0}$ Design

There is a meaningful relevancy between structural factors and enriching the managers of branches of Saderat bank in Tehran.

$\mathrm{H}_{0}: \mathrm{p}: 0$

Theory $\mathrm{H}_{1}$ Design

There is a meaningful relevancy between structural factors and enriching the managers of 
branches of Saderat bank in Tehran.

$\mathrm{H}_{1}: \mathrm{p} \neq 0$

Table 4. Pierson's correlation test, between structural factors and enriching

\begin{tabular}{llll}
\hline Variables name & Correlation test & Sig number & $\begin{array}{l}\text { Meaningful } \\
\text { relevancy }\end{array}$ \\
\hline Enriching & $0 / 710 * *$ & $0 / 000$ & exists \\
\hline
\end{tabular}

According to SPSS outcome, Pierson's correlation index for these two variables is $0 / 710$. The amount of observed "sig" is $0 / 00$ and is below 0/01 which is below standard meaningfully level $(\infty=\% 1)$. Therefore, Theory $\mathrm{H}_{0}$ is rejected with 99 percent of certainty, which means there is a meaningful relevancy between these two variables.

\section{Regression}

After making sure that there is correlation between structural factors and enriching regression, can be used to recognize the amount of effects of structural factors on enriching.

The test of theories related to regression and variance analysis

(A)Regression between structural factors and enriching

$\mathrm{H}_{0}$ Theory design

There is not enough evidence proving that there is a linear relevancy between enriching and structural factors.

$\mathrm{H}_{0}: \beta=0$

$\mathrm{H}_{1}$ Theory design

There is enough evidence proving that there is a linear relevancy between enriching and structural factors.

$\mathrm{H}_{1}: \beta \nRightarrow$ 
Table 5. Regression of structural factors and enriching

\begin{tabular}{|c|c|c|c|c|c|}
\hline \multirow[t]{3}{*}{ Model } & \multicolumn{2}{|c|}{ Irregular Beta } & \multirow{3}{*}{$\begin{array}{l}\text { Standard } \\
\text { Beta } \\
\text { beta }\end{array}$} & \multicolumn{2}{|c|}{ Test statistics } \\
\hline & & & & & sig \\
\hline & Beta & Beta error & & & \\
\hline (stable) & 0.265 & 1.66 & & 1.592 & 0.113 \\
\hline \multicolumn{6}{|c|}{ Structural } \\
\hline factor & 0.909 & 0.57 & 0.710 & 16.033 & 0.000 \\
\hline
\end{tabular}

According to SPSS outcome, the statistics amount of the test $(\mathrm{t}=16.033)$ is more than critical amount of the Table $\left(\mathrm{t}_{0} .05_{\mathrm{n} ; \mathrm{n}-2}=1.645\right)$.

Therefore, $\mathrm{H}_{0}$ theory indicating linear relevancy between structural factors and enriching, is rejected.

In other words, there is enough evidence indicating that there is a linear relevancy between structural factors and enriching.

Note (1): Rejecting theory $\mathrm{H}_{0}$ means that intercept of regression equation is not zero. Therefore, the regression equation of the 2 structural and enriching variables is: $\mathrm{Y}=0.265+0.0909_{\mathrm{x}}$

Note (2): According to the fact that 'sig' is 0.000 and is below standard level of meaningfully $(\infty=0.05)$, therefore, regression model has been able to explain changes independent variable (enriching).

Note (3): Regular Beta amounts indicate the importance of every one of the predictors in model. The more this amount, the more important it is $(\beta=0.71)$.

\section{RESULTS AND DISCUSSION}

Among structural variables; although authority conferment with the average of 3.28, enriching job with the average of 3.05 and officialdom with the average of 3.19 have gained averages above 3 , it needs the improvement of quantitative and qualitative level of studied variables for reaching the fine extent.

The result of analyzing information indicates that there is a meaningful relevancy between 
structural factors and enriching the managers of Saderat bank branches in Tehran.

According to pierson's correlation test, this variable has the meaningfully index of 0.000 and is below 0.01; At the same time numerical value of Pierson's correlation index is 0.71 , Therefore H0 theory is rejected with the certainty of $99 \%$ which means there is a meaningful relevance between these 2 variables.

These results, also deal with the results of regression, that calculated SIG is 0.000 and below meaningfully standard level $(\infty=0.05)$, Therefore regression has been able to explain these changes independent variable (enriching)

Comparison to other investigations

Eskandari investigation; this investigation has 10 theories in which the theories related to talent, attitude, manager's personality, head manager's leadership style, organizational structure type, awarding system and organizational atmosphere have been rejected and have become punctual by the structural branch of the relevance between job designing and enriching.

Light (2004): It's about staff communication with 4 effective factors including information, authority, award, knowledge, communication with staff capability amount with the aspect of having the right to choose, self-efficiency, having affection job and meaningfully and it's connection with job satisfactory. Except the variable "having the right to choose" in Light's investigation, other factors indicate a good relevance in the present investigation too, the variables "information" and "award" are considered among effective factors on staff enriching.

\section{CONCLUSION}

$\checkmark$ Enriching is an active process. It means a long time must be spent on it and there can't be a special level called incapability or capability. As there can never be any limits for knowledge and skill. Enriching is in need of great managers and related programs must start from top of organization pyramid. Because capable managers enrich others.

$\checkmark$ In designing every pleasant situation for the system for the system of human resources and introducing solutions for reforming, actions must be taken about pathology of 
present condition and since the conditions change as time passes, the process of pathology should be updated regularly, too. In the pathology of the system of human resources of the bank, the two points of view (staff and managers) should be used and staff comprehension of current condition results, must be compared with actual function of enriching field of the bank.

$\checkmark$ So that a general comprehension happens in this field and the required programming for improvement happen in order to reform educational system and designing educational programs related to bank goals and great strategies, it is suggested that firstly, actual jobs get reckoned by using some organizational documentation such as organizational diagram, revising the explanation of available jobs and having introduction with some deputies and head managers and then the jobs should be grouped. At the next level, all jobs should be reanalyzed using new attitudes such as ONET, and a list of knowledge, skills and abilities and appropriate nesses required for every job, must be prepared and according to analyzed jobs, strategic educating program commensurate with virtual educating attitude, must be determined.

$\checkmark$ Organizational justice at bank must be guaranteed, which means that the processes must be located fairly and managers must appreciate stuff positive function fairly and logically and they should support them.

$\checkmark$ In bank, a vocational progress and vocational promotion must be designed from inside and fairly and empty management positions must be filled with adequate staff.

$\checkmark$ Authority conferment with the average of 3.28 is one of the priorities of enriching in this investigation. Therefore, a situation must be provided that by leaving more authority to the staff and managers for making decisions, doing some activities and more control on jobs be left on the shoulder of staff, if authority conferment is accompanied with trust, it'll be considered as a strong motive, because we try to do our responsibilities accurately due to accountability.

$\checkmark$ Since the condition of every structural factor of every organization is affected by human resources base, generalized reforming of human resources base is considered a precondition in designing the adequate model of Saderat-Iran bank structure therefore, 
using experienced advisor's and university professors, for the better conferment of human resources sub systems (such as optimization subsystem) in this field, can be helpful.

$\checkmark$ Enriching staff happens, only if co-management is attendant with authority conferment and people's function gets improved by awarding them according to their function. The process of enriching is a step by step and gradual process and therefore, the enriching programs of organization, must be started by job enrichment. In this stage, sufficient authority must be left to staff according to their responsibilities and provided that a successful function is produced, they are worthy of rewards. After job enrichment, holding a suggestion system matters almost too much. In the system of suggestion, people should be allowed to have further cooperation permission (offering suggestions) in actions related to their organizational unit and provided that useful suggestions are given, they must be appreciated coordination with their efforts. Once the staff are approximately enriched with required skills and mental maturity for having cooperation in matters, the organization must allow them to make decision by making functional teams and providing exchange views and denial in order to encourage staff to participate in groups and increasing team function

\section{REFERENCES}

[1] Abby Kahaleh, B. Pharm, Caroline Gaither.The effects of work setting on pharmacists' empowerment and organizational behaviors. Research in Social and Administrative Pharmacy 2007, 3, 199-222.

[2] Adam Rapp, Michael Ahearne, John Mathieu, Niels Schillewaert. The impact of knowledge and empowerment on working smart and working hard: The moderating role of experience. international Journal of Research in Marketing. 2006, 23, 279-293

[3] Azize Ergeneli, Guler Saglam Ari, Selin Metin. Psychological empowerment and its relationship to trust in immediate manager. Jornal of Business Research 2007, 60, 41-49.

[4] Catherine Cheung, Tom Baum, Alan Wong. Relocating empowerment as a management 
concept for Asia.Jornal of Business Research 2012, 65, 36-41.

[5] Debbie Massey, Debora Osborne. Empowerment and assessment: a dichotomy? Nurse Education Today 2004, 24,357-362.

[6] Esther Gal-Or, Raphael Amit. Does empowerment lead to higher quality and profitability? Journal of Economic Behavior and Organization vol. 1998, 36, 411-431.

[7] Gretchen M. Spreitzer, Mark A. Kizilos, Stephan W. Nason. A Dimensional Analysis of the Relationship between Psychological Empowerment and Effectiveness, Satisfaction, and Strain, EJBO Electronic Journal of Business Ethics and Organizational Student vol. 1997, 23, No.5

[8] Jon Sundbo. The Balancing of Empowerment a Strategic Resource Based Model of Organizing Innovation Activities in Service and Low-Tech Firms. 1996.

[9] Jorn Flohr Nielsen, Christian Preuthun Pedersen. The consequences and limits of empowerment in financial services, Scandinavian Journal of Management, pergamon, scand.J.Mgmt. 2003, 19, 63-83.

[10]Kenneth J. Harris, Anthony R. Wheeler, K. Michele Kacmar. Leader- member exchange and empowerment: Direct and interactive effects on job satisfaction, turnover intentions, and performance. The Leadership Quarterly 2009, 20, 371-382.

[11]Lame C.Jay, Kevin L. Webb, Chiharu Ishida. Self- managing selling teams and team performance: The complementary roles of empowerment and control. Industrial Marketing, 2009, 38, 5-16.

[12]Scott, Jaffe DT, CD. Empowerment.Iran nejad M, editor,1st ed. Tehran: Institute of Education and Research in Management 2004.p.85-110. (Persian).

[13] Shazia Nauman, Azhar Mansur Khan, Nadeem Ehsan. Patterns of Empowerment and Leadership Style in Project Environment.International Journal of Project Management 2010, 28, 638-649.

[14] Tae- Yeol Kim, Minsoo Kim.Leaders' Moral Competence and Employee Outcomes: The Effects of Psychological Empowerment and Person- Supervisor Fit. Springer Science +Business Media B.V.2012.

[15]W.Alan Randolph,.Navigating the Journey to Empowerment. 2004 
[16] Yuosre F.Badir, Bettina Buchel, Christopher L.Tucci. A Conceptual framework of the impact of NPD project team and leader empowerment on communication and performance: An alliance case context. International Journal of Project Management 2012, 30, 914-926.

\section{How to cite this article:}

Tabrizi N. The relevancy between structural factors and enriching the managers of saderat bank branches in Tehran province. J. Fundam. Appl. Sci., 2016, 8(2S), 257-275. 